\title{
TOWARDS KNOWLEDGE EXCHANGE FOR EFFECTIVE INNOVATION SUPPORT
}

\author{
Chris Roast, Elizabeth Uruchurtu and Tonderai Maswera \\ Department of Computing and Computing \& Communication Research Centre \\ Sheffield Hallam University, Sheffield, United Kingdom
}

\begin{abstract}
The term Knowledge Exchange (KE) is commonly used to describe university-industry collaborations that frequently foster innovation. Understanding such collaborations and their potential value is a difficult activity. The means of supporting collaboration vary significantly and potential for successful innovation is hard to asses. In this paper, we describe work aimed at developing an improved understanding of knowledge exchange within a digital context - both within digital sectors and also in non-digital sectors where the adoption of digital technologies can lead to new and challenging opportunities. Our work focuses upon digital innovation for Small to Medium Enterprises (SMEs) aiming to support effective Knowledge Exchange based innovation; a specific driver being the difficulty of understanding the potential for successful and productive collaborations with individual SMEs. From a number of existing digital innovation models and instruments, factors for characterizing digital innovation potential have identified. However, based on our experience and expert feedback, such characterizations appear to be inappropriate for SMEs. In response to this, an instrument has been developed to identify potential for quality digital innovation based on collaborative KE between SMEs and universities. The instrument is introduced, and its development and refinement discussed.
\end{abstract}

\section{KEYWORDS}

Digital Innovation, Knowledge Exchange, Innovation Support

\section{INTRODUCTION}

Innovation is widely seen as an essential component of commercial growth within industry (Abrell et al., 2016). It offers the prospect of development that is not based on incremental changes to business models and processes improvements. So instead of simply focusing upon doing more of the same more efficiently, an innovation focus may develop new products and services, revising and disrupting tried and tested models of operation and distribution. The research reported here is motivated by the assumption that the characteristics of digital technology often facilitate innovation: "...computing devices are no longer isolated but connected by increasingly ubiquitous communication networks. Mobile devices and pervasive applications link their users to networked applications and to other people almost permanently. The nascent 'Internet of things' and digital/material 'hybrid' objects are beginning to link what we have to come to think of as distinct 'virtual' reality to the reality of everyday material objects." (Walker et al., 2012).

Hence, it is important to understand the mechanisms behind digital innovation and how best to assess digital innovation potential. Of additional relevance is the significant challenge regarding how to make the best of digital innovations within business, including technological, financial, organizational and regulatory (Ramilo et al., 2014). In particular, the impact of disruptive innovations can be hard to predict. As Berkhout and Duin (2004) put it: "...merely investing in product development does not suffice in a competitive digital industry".

Our research is framed by two foci that reflect governmental strategic initiatives to drive innovation and economic growth:

Third party bringers of innovation - This refers to the role adopted often by agencies and consultants, to explicitly mentor or enable innovation within a company (with some level of governmental support). This approach can be criticized for: not benefiting from a detailed knowledge of a company's business domain; being relatively short term; and not instilling innovation within a company. However, the government sponsorship can be easily managed, monitored and resource-framed. It should be noted that in terms of 
management of innovation, value comes from collaborations (such as joint-ventures), as opposed to the transactional perspective offered by third party innovators (BSi, 2008). In this paper, the third party we are interested in is that of University expertise. Unlike consultants and professional agencies, Universities provide access to expert knowledge and insight, and thus have an interest in ensuring that their own knowledge and research expertise are employed. Hence, they are not simply facilitators but also want to actively engage in transferring or applying knowledge. Past evidence suggests that partnerships with external stakeholders have led to successful co-creation processes (Markovica \& Bagherzadehb, 2018).

SMEs and Innovation - SMEs are commonly of interest given their strategic economic relevance (Higón, 2011). Broadly speaking, they tend to be more opportunistic and flexible, and while often valuing innovation they are commonly not in a position to de-risk an innovation process (Auzzir et al., 2018; Beck \& Demirgruc-Kunt, 2006; Garcia-Perez-de-Lema et al., 2017; Liang et al., 2017; Ramilo et al., 2014). Specifically, in our experience, for digital innovative products and services "speed to market" is often prioritized by SMEs in the digital sector.

The problem we wish to address is from the perspective of a "third party bringer of innovation" with digital expertise and experience, aimed at serving and supporting SMEs:

\section{How can companies be helped to identify opportunities for innovation with digital technologies?}

There are many facets to this problem. Lack of financial resources has been identified as one of the major barriers to innovation for SMEs (Madrid-Guijarro et al., 2009). Furthermore, a study carried out by showed that SMEs struggle to implement digital technologies due to their inability to adapt to changes. Generating innovation ideas has not been a problem for SMEs but failure to translate these ideas into "comprehensive innovations"(Najda-Janoszka \& Kopera, 2014). This is reiterated in a study Quinton et al., (2017) in which it was concluded that SMEs need support in understanding the environment in which they operate to succeed in digital innovation.

The above suggests that a company's "innovation maturity" is most relevant since innovation may be enabled or inhibited by organizational and operational factors. Therefore, while digital innovation is our explicit focus, opportunities in the business context will normally be the key motivator. To gain a deeper understanding of this problem, we have reviewed a number of characterizations of innovation and used them to support the development of an instrument to assist with scoping and assessing the potential for collaborative innovation. Since our institution is actively engaged as a third party innovator for SMEs, we have good access to various stakeholders in such processes. Its design, development and refinement will provide key insights into the problem of helping identify innovation opportunities with digital technologies.

\subsection{Challenges of Knowledge Exchange}

Within Higher Education (HE) Knowledge Exchange (KE) is a term used to capture a variety of academic and industry collaborations (Wehn \& Montalvo, 2018; Lin \& Wei, 2018). In the broadest sense, it can range from research dissemination to public and professional courses (Continuing Professional Development - CPD); through to an academic-based contribution to business and industry, and commercialization of intellectual property (see Wilson, 2012; Witty, 2013; Dowling 2015). In the context of this work, we focus upon the value of academic collaboration with industry that has relevance for one or both parties:

- There is a strategic and sometimes financial value for academia to realize the benefits of applying their knowledge and expertise in a commercial setting. The classical view being that of arrow projects (Witty, 2013), where a research discovery or insight forms the core basis for a future product, patent or service. The same value is recognized through the concept of research impact - a core element of UK research excellence framework (Stern, 2016; REF, 2017).

- There is a pedagogic value to knowledge transfer activity for academia in that it strengthens academic awareness of contemporary practice in industry that can underpin, inform and direct pedagogic objectives and practice. Strong academia-firm interactions have positive impact on innovativeness of SMEs (Jones \& Corral de Zubielqui, 2017).

- There is an industrial value to being able to access expertise and knowledge in specific domains. Academic awareness of state of the art practice has the potential to contribute to product and process improvement and growth. 
While this is not an exhaustive list of opportunities, it characterizes some key scenarios. It is important to note that the different perspectives do not necessarily align. For example, the academic desire to publish research findings is at odds with an industrial desire to gain commercial advantage from the same insights.

\subsection{Challenges and Opportunities of Digital Innovation}

Digital innovation has over the years presented companies with a competitive edge in many respects. Numerous examples exist in e-commerce and social media. Commonly, digital innovation is enabled within many business contexts as a result of:

- The dissolution of traditional boundaries regarding location, distance, scale or timeframes.

- The improved automation of processes -i.e. transformation of boundaries of skills, ability and agency, etc. (see: Roast et al., 2011)

- Access to more data (quantity and quality) and the potential for greater transparency and/or insight.

Nylén and Holmström (2014) point out that the resulting opportunities can be overlooked because of managers lack knowledge about digital technology and its potential. They highlight that research in digital innovation has not progressed as much as innovation research in other fields. In particular it can be argued that digital innovation opportunities need to be managed differently, in order to effectively accommodate:

- Intangibility - The different pace of digital innovation processes due in part to the intangible nature of digital products and services and their easy entry production methods when compared with physical production.

- Reach - The prevalence of digital adoption and integration means that innovations have the potential to skew the very business assumptions on which they were based.

- Induction -Provide a richer understanding of the world (Holmström, 2018).

\section{INNOVATION FRAMEWORKS}

There are a number of innovation frameworks; those of immediate relevance to this research are diagnostic in nature and explicitly relevant to digital innovation, including: Barbieri \& Teixeira Álvares, 2016; Berkhout \& Duin, 2004; Binz \& Trufer, 2017; BSi, 2008; Carayannis et al., 2018; Scaringella \& Chanaron, 2016; Chen et al., 2018; Gkypali et al., 2018; İzadi et al., 2013; Nylén \& Holmström, 2014; Silviana, 2018. Specifically, Berkhout \& Duin (2004), BSi (2008), and Nylén \& Holmström (2014) each present an interesting range of perspectives: technology-cyclic, innovation management, and components of digital innovation, respectively. Core features from each are used to help develop our understanding of digital innovation, and also inform our instrument design.

\subsection{Cyclic Innovation}

The cyclic innovation model (Berkhout \& Duin, 2004) is motivated by the fast-paced technological and market developments in the telecommunications industry and how they have continually influenced the way companies innovate. It encourages a non-linear view where feedback is core, linking: market; product; technology and science. This gives four interacting "cycles of change" (Figure 1), intending to reflect the complex, contemporary cross-boundary innovation processes. 


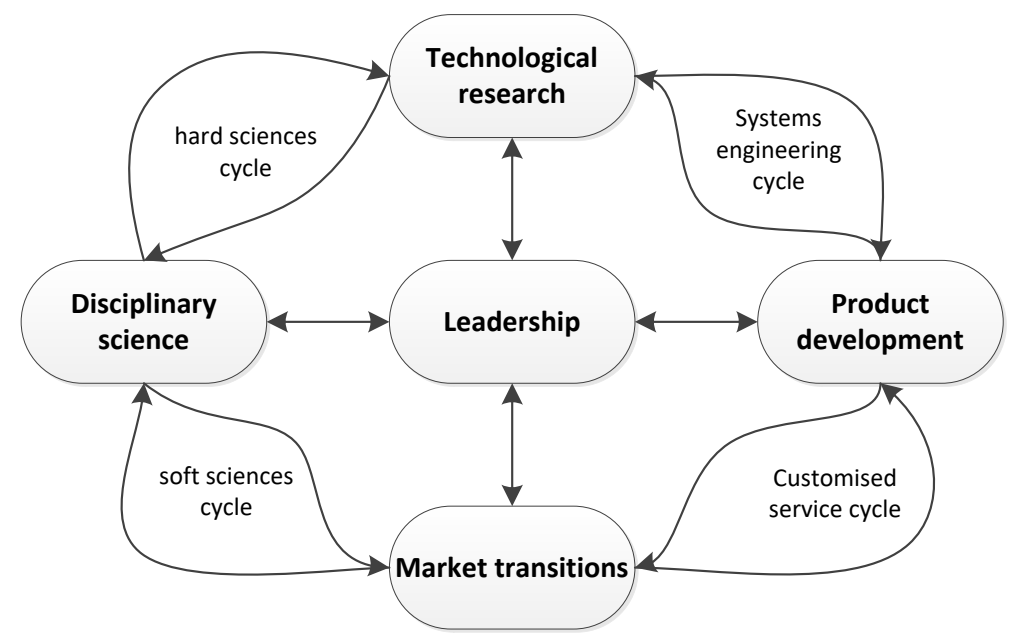

Figure 1. The Cyclic Innovation Model (Berkhout \& Duin, 2004)

The model was originally used to analyze the introduction of a mobile data service into the Dutch telecommunication market. Berkhout and Duin (2004) discuss the complex nature of this specific venture, where a number of stakeholders contributed to the design and implementation of the service. In this specific case study, innovations and activities within the model center on the market and product. In their account of the innovation the relevance of technology is low and with science playing not explicit role. Hence in this example, innovation happened through the "Customized service cycle" and the "Systems engineering cycle" iteratively.

The model illustrates that different innovation processes exist depending upon domains and cycles engaged. The validity of this perspective can be found in many digital examples. From a digital focus, Science and Technology largely predicates innovations that are closely allied to Market transitions through customer engagement (and customer/market creation). Examples, such as UBER and many others illustrate this point - the technological infrastructure used has not purposefully driven the innovation. That said, the model also entertains a "reverse" flow from product concept to technological and scientific research. Some digital examples where product need has driven technological advances might be evident in Internet of Thing (IoT) development and cyber security.

In terms of our research aims, the model substantiates the view that innovation engages many facets of value that are not purely led by technology, or themselves digital. As we have observed above, the model also supports the point that digital results in innovations gain their value in "non-digital" contexts. The context of University support and knowledge transfer the framework indicates how discipline expertise may have a focused contribution to specific activities.

\subsection{Innovation and Design Management Standards}

BS 7000-1:2008 Design management systems (BSi, 2008) focuses upon strategy, managerial structures, features and mechanisms that support innovation, and as such provides little information about the mechanisms of innovation. It takes the form of guidance and recommendations for supporting innovation that are to be used selectively and adaptively to suit the needs of an organization. As such, it is more focused upon the organizational mechanisms to enable, monitor and sustain an innovation culture. The overarching focus is upon identifying and meeting customer needs or drawing in new customers in a competitive market. Consequently the emphasis is mainly upon product and market.

The management perspective rather encourages adoption by organizations with an adequate managerial structure, and thus is not ideal for small enterprises. However, many of the innovation techniques collated are techniques widely adopted in many digital SMEs, especially those working in the B2C context.

Also of use within the standard are a number of checklists and diagnostics for assessing innovation within a company. However it is of interest to note that when we have trialed such checklist a number of cases have been imprecise and unclear to those attempting to use them. 


\subsection{Managing Digital Innovation}

The framework of Nylén and Holmström (2014) is a product of research examining the innovation processes and the challenges and demands of new technologies. In order to be able to properly manage uncertainties brought about by innovation driven by digital technologies three dimensions were identified: digital product/service; digital environment, and characteristics of the organization. Within these, five areas were proposed as relevant to managing digital innovation:

Digital product/service

- User experience- The focus of products should include usability, engagement and aesthetics as users are affected and influenced by what the product looks like.

- Value proposition- Organizations need to clearly define the value proposition of the new product or service; that is, to assess the revenue from the digital product or service which goes to distribution networks. Evaluating of the value proposition is based upon customer segmentation and coverage.

Digital Environment

- Digital evolution scanning- Firms need to continuously gather information about new and upcoming digital technologies to driving innovation and also reach prospective users. (This mirrors the innovation tactic of "horizon scanning" endorsed in the BSi document).

Characteristics of the Organization

- Skills- The rapid pace at which the digital innovation process occurs needs to be matched by the skills available within a company. The framework evaluates this process by looking at ways in which learning is supported and promoted - in particular significant value is placed on the opportunity to learn by experimentation and exploration.

- Improvisation- The pervasive nature of digital technologies undermines traditional ways of designing and developing new products and services. This framework promotes innovation through "improvisation". It is recommended that staff be given time and space to promote creativity and innovation.

Nylén and Holmström (2014) devised a diagnostic tool capable of scoring digital innovation readiness, and providing a focus for discussion and improvement. This approach has been developed for the purposes of internal review of innovation practice within companies developing digital media. While our focus is on KE and SMEs in a wider range of industries, the dimensions proposed, and their components can be repurposed for a wider context.

\section{INSTRUMENT DEVELOPMENT AND REFINEMENT}

\subsection{The Process}

Observations and reflections on the frameworks examined have helped motivate the development of a pilot diagnostic instrument aimed at helping SMEs identify opportunities for innovation with digital technologies. The instrument initially combined ideas from all three frameworks discussed above; with early versions being cumbersome and, to some extent, repetitive and ambiguous. This lead to a number careful reviews, analyses and refinements by the authors to reduce an instrument with realistic scale and improved its precision. The rational for individual instrument items was recorded to inform future revisions.

The instrument comprises a series of statements aiming at ascertaining a company's business strategy, and their approach to innovation and product/service development and value proposition. Also, company's understanding of their market, segments and customer expectations, attitude to digital horizon scanning, and approach to the development of knowledge and skills among staff.

\subsection{Feedback and Refinements}

The initial instrument developed was collaboratively assessed by nine KE professionals, ranging from 2 to $25+$ years of experience in $\mathrm{KE}$ and Innovation roles within the University. On the whole, feedback was positive with most critical points concerning: operational specifics about how to use it, the intended digital focus, and the importance of managing company expectations of KE. 
Resulting refinements reduced the number of question statements. One concerning issue was to ensure that, within relatively few statements, the focus did not move between specific innovation projects and general company-wide policies/aims related to innovation. Although both perspectives were relevant, when combined they were judged to undermine the instrument's acceptance. To help resolve this, the instrument statements were redesigned to be project focused, while alluding innovation management in general. The resulting statements led to further similarities that could be removed as redundant.

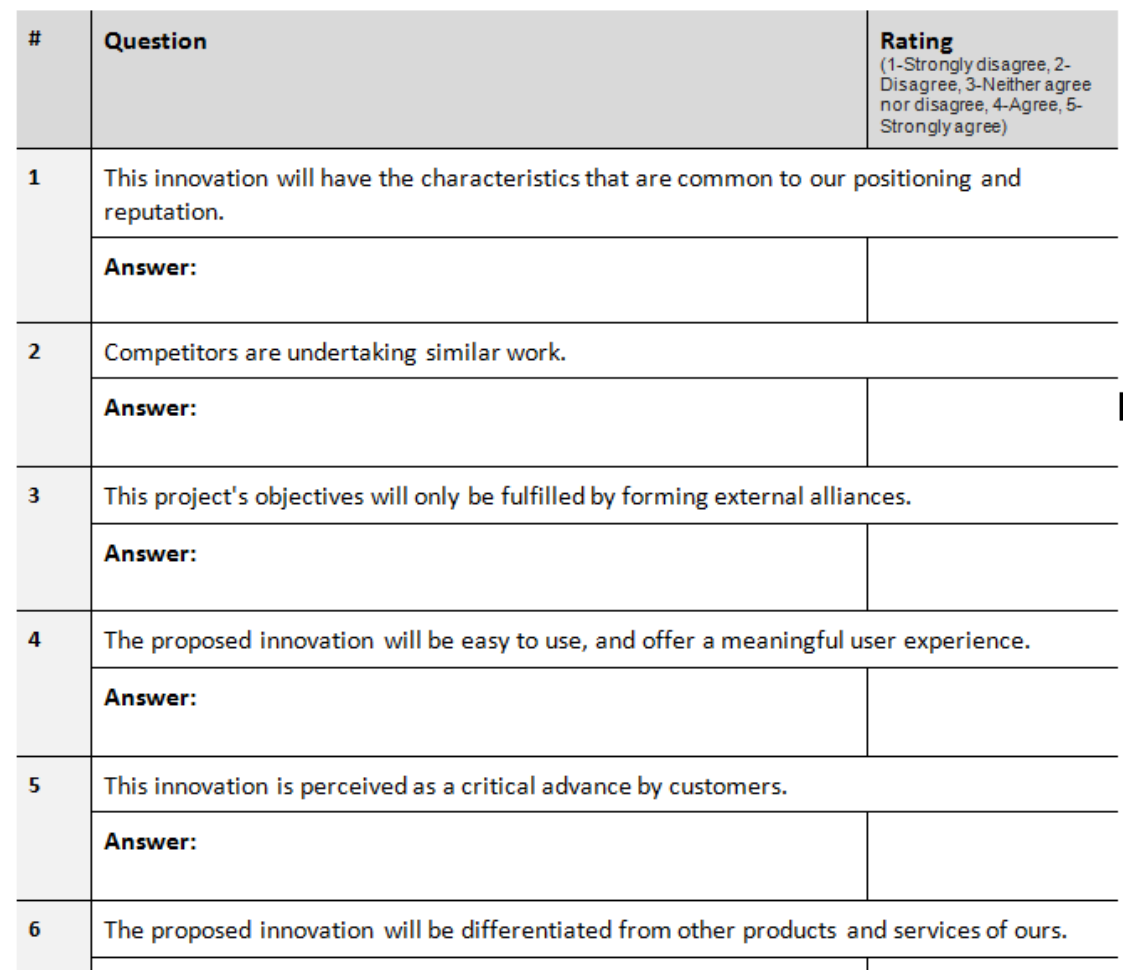

Figure 2. An extract of the current version of the instrument

The latest version of the instrument (Figure 2) has been assessed in consultation with local companies known to have an interest in innovation. However, early findings from this round of assessment suggest that the instrument has the potential to help SMEs plan for digital innovations: participants in this evaluation expressed that the statements and questions in the instrument provided an opportunity for critically thinking about issues that they might have not considered otherwise. It has also helped identifying areas where support is required - University's expertise, for example.

Further work has also been identified. For example, the purpose of using the instrument was not immediately clear for some of the companies participating. Also, whether the data gathered through the instrument can have any further value beyond individual projects is a matter of future consideration - i.e. can the scores and open-ended answers be used to compare projects? Would that be of any benefit?

As expected, issues of novelty and value of digital technologies surfaced during the assessment process among different types of businesses. For example, for one of the participating companies the use of Augmented Reality was not really novel, but certainly strategic given their current business context.

Once the feedback received has been fully considered, the individual statements in the instrument and their relevance will be re-assessed and the instrument refined. 


\section{CONCLUSIONS}

The distinctive nature of digital innovation is not easily identified in existing frameworks for characterizing innovation, especially within the context of SMEs where there can be light management structures, tacit innovation goals and limited resources. Our interest in this project also lies on university-industry collaborations that can foster innovation. Relevant work in this field has demonstrated that organizations are likely to achieve innovation success through co-creation with external stakeholders willing to actively engage in knowledge and expertise exchange.

Here, we have discussed work carried out aimed at understanding Knowledge Exchange within a digital context. Following an analysis of published innovation frameworks, a number of key features have been identified and used to develop our own pilot instrument for addressing our original question: How can companies be helped to identify opportunities for innovation with digital technologies?

The early versions of the instrument have been received positively by HE intermediaries and it has been trialed with a view to gaining formative feedback with some of local SMEs. The next stage of this project is a further refinement, prior to applying the instrument within digital innovation opportunities coming from a current innovation program for supporting SMEs.

\section{ACKNOWLEDGEMENTS}

We are indebted to local companies, University staff and Andre Meier (MSc's student) who have contributed time and reflections to inform the research reported. The work has benefited from the Sheffield Innovation Programme (a regional development initiative supported by the EU);

\section{REFERENCES}

Abrell, T., Pihlajamaa, M., Kanto,L., vom Brocke, J. \& Uebernickel, F. (2016). The role of users and customers in digital innovation: Insights from B2B manufacturing firms. Information \& Management, 53 (3), 324-335, https://doi.org/10.1016/j.im.2015.12.005.

Auzzir, Z., Haigh, R. \& Amaratunga, D. (2018). Impacts of Disaster to SMEs in Malaysia. Procedia Engineering, 212, 1131-1138. https://doi.org/10.1016/j.proeng.2018.01.146.

Barbieri, J. C., Teixeira Álvares, A. C. (2016). Sixth generation innovation model: description of a success model. RAI Revista de Administração e Inovação, 13 (2), 116-127. https://doi.org/10.1016/j.rai.2016.04.004.

Beck, T. \& Demirguc-Kunt, A. (2006). Small and medium-size enterprises: Access to finance as a growth constraint. Journal of Banking \& Finance, 30(11), 2931-2943. https://doi.org/10.1016/j.jbankfin.2006.05.009.

Berkhout, G. \& Duin, P.V.D. (2004) Mobile Data Innovation: Lucio and the Cyclic Innovation Model. ICEC'04, Sixth International Conference of Electronic Commerce. Janssen, M. et al. (Eds.). ACM, pp. 603-608

Binz, C. \& Truffer, B. (2017). Global Innovation Systems-A conceptual framework for innovation dynamics in transnational contexts. Research Policy, 46 (7), 1284-1298. https://doi.org/10.1016/j.respol.2017.05.012.

BSi (2008). Design management systems. Part 1: Guide to managing innovation. BS 7000-1:2008. 3rd Ed., British Standards Institution.

Carayannis, E. G., Goletsis, Y. \& Grigoroudis, E. (2018). Composite innovation metrics: MCDA and the Quadruple Innovation Helix framework. Technological Forecasting and Social Change, 131, 4-17. https://doi.org/10.1016/j.techfore.2017.03.008.

Chen, J., Yin, X. \& Mei, L. (2018). Holistic Innovation: An Emerging Innovation Paradigm. International Journal of Innovation Studies, https://doi.org/10.1016/j.ijis.2018.02.001.

Dowling (2015). The Dowling Review of Business-University Research Collaborations July 2015. https://www.raeng.org.uk/policy/dowling-review/the-dowling-review-of-business-university-research

Garcia-Perez-de-Lema, D., Madrid-Guijarro, A. \& Martin, D. P. (2017). Influence of university-firm governance on SMEs innovation and performance levels. Technological Forecasting and Social Change, 123, 250-261. https://doi.org/10.1016/j.techfore.2016.04.003. 
Gkypali, A., Arvantis, S. \& Tsekouras, K. (2018), Absorptive capacity, exporting activities, innovation openness and innovation performance: A SEM approach towards a unifying framework. Technological Forecasting \& Social Change. https://doi.org/10.1016/j.techfore.2018.01.025

Higón, D. A. (2011). The impact of ICT on innovation activities: Evidence for UK SMEs. International Small Business Journal, 30 (6), 684 - 699. https://doi.org/10.1177/0266242610374484

Holmström, J. (2018), Recombination in digital innovation: Challenges, opportunities,and the importance of a theoretical framework, Information and Organisation, 28: 107-110, https://doi.org/10.1016/j.infoandorg.2018.04.002

İzadi, A., Zarrabi, F. \& Zarrabi, F. (2013). Firm-Level Innovation Models. Procedia - Social and Behavioral Sciences, 75, 146-153. https://doi.org/10.1016/j.sbspro.2013.04.017.

Jones, J. \& Corral de Zubielqui, G. (2017). Doing well by doing good: A study of university-industry interactions, innovationess and firm performance in sustainability-oriented Australian SMEs. Technological Forecasting and Social Change, 123, 262-270. https://doi.org/10.1016/j.techfore.2016.07.036.

Liang, L-W., Huang, B-Y, Liao, C-F \& Gao, Y-T (2017). The impact of SMEs' lending and credit guarantee on bank efficiency in South Korea. Review of Development Finance, Vol 7 (2), 134-141, https://doi.org/10.1016/j.rdf.2017.04.003.

Lin, M. \& Wei, J. (2018). The impact of innovation intermediary on knowledge transfer. Physica A: Statistical Mechanics and its Applications, 502, 21-28. https://doi.org/10.1016/j.physa.2018.02.207.

Madrid-Guijarro, A., Garcia, D. \& Van Auken, H. (2009). Barriers to Innovation among Spanish Manufacturing SMEs. Journal of Small Business Management, 47: 465-488. doi:10.1111/j.1540-627X.2009.00279.x

Markovica, S. \& Bagherzadehb, M. (2018). How does breadth of external stakeholder co-creation influence innovation performance? Analyzing the mediating roles of knowledge sharing and product innovation. Journal of Business Research Vol. 88, pp. 173-186. https://doi.org/10.1016/j.jbusres.2018.03.028

Najda-Janoszka, M. \& Kopera, S. (2014), Exploring Barriers to Innovation in Tourism Industry - The Case of Southern Region of Poland, Procedia - Social and Behavioral Sciences, 110: 190-201, https://doi.org/10.1016/j.sbspro.2013.12.862

Nylén D. \& Holmström, J. (2015). Digital innovation strategy: A framework for diagnosing and improving digital product and service innovation. Business Horizons, 58(1), 57-67. https://doi.org/10.1016/j.bushor.2014.09.001.

Quinton, S., Canhoto, A., Molinillo, S., Pera, R. \& Budhathoki, T. (2018), Conceptualising a digital orientation: antecedents of supporting SME performance in the digital economy, Journal of Strategic Marketing, 26:5, 427-439, DOI:10.1080/0965254X.2016.1258004.

Ramilo, R., Rashid, M. \& Embi, B. (2014). Critical analysis of key determinants and barriers to digital innovation adoption among architectural organizations. Frontiers of Architectural Research, 3 (4), 431-451. https://doi.org/10.1016/j.foar.2014.06.005.

REF 2017, Initial decisions on the Research Excellence Framework 2021. http://www.ref.ac.uk/media/ref,2021/downloads/REF2017_01.pdf

Roast, C., Dearden, A. \& Uruchurtu, E. (2011). Using and utilizing an innovative media development tool. Proceedings of the 10th Brazilian Symposium on Human Factors in Computing Systems, and the 5th Latin American Conference on Human-Computer Interaction. Porto Alegre, Brazil. ACM, 149-156.

Scaringella, L. \& Chanaron, J. J. (2016). Grenoble-GIANT Territorial Innovation Models: Are investments in research infrastructures worthwhile? Technological Forecasting and Social Change, 112, 92-101. https://doi.org/10.1016/j.techfore.2016.05.026.

Silviana, B. G. (2018). Open innovation model: enabling the market uptake of innovation. Procedia Manufacturing, 22, 893-899. https://doi.org/10.1016/j.promfg.2018.03.126.

Stern (2016). Building on Success and Learning from Experience an Independent Review of the Research Excellence Framework. https://www.gov.uk/government/uploads/system/uploads/attachment_data/file/541338/ind-16-9-refstern-review.pdf

Walker, S., Bell, S., Jackson, A. \& Heery, D. (2012). Imagine real avatars and flying shepherds: involvement and engagement in innovative ICT. PCD'12. Roskilde, Denmark: ACM. 101-108.

Wehn, U. \& Montalvo, C. (2018). Knowledge transfer dynamics and innovation: Behaviour, interactions and aggregated outcomes. Journal of Cleaner Production, 171, S56-S68. https://doi.org/10.1016/j.jclepro.2016.09.198.

Wilson (2012) A Review of Business-University Collaboration Professor Sir Tim Wilson DL February 2012 https://www.gov.uk/government/uploads/system/uploads/attachment_data/file/32383/12-610-wilson-reviewbusiness-university-collaboration.pdf

Witty (2013) Encouraging a British Invention Revolution: Sir Andrew Witty's Review of Universities and Growth. https://www.gov.uk/government/uploads/system/uploads/attachment_data/file/249720/bis-13-1241-encouraging-abritish-invention-revolution-andrew-witty-review-R1.pdf 